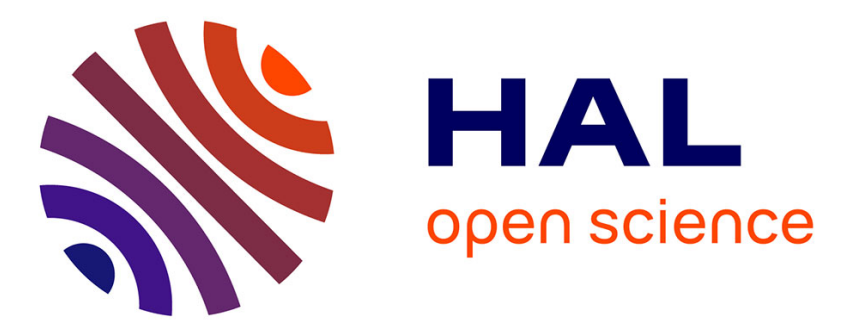

\title{
PLM in SME, What Are We Missing? An Alternative View on PLM Implementation for SME
}

\author{
Bas Koomen
}

\section{To cite this version:}

Bas Koomen. PLM in SME, What Are We Missing? An Alternative View on PLM Implementation for SME. 15th IFIP International Conference on Product Lifecycle Management (PLM), Jul 2018, Turin, Italy. pp.681-691, 10.1007/978-3-030-01614-2_62 . hal-02075627

\section{HAL Id: hal-02075627 \\ https://hal.inria.fr/hal-02075627}

Submitted on 21 Mar 2019

HAL is a multi-disciplinary open access archive for the deposit and dissemination of scientific research documents, whether they are published or not. The documents may come from teaching and research institutions in France or abroad, or from public or private research centers.
L'archive ouverte pluridisciplinaire HAL, est destinée au dépôt et à la diffusion de documents scientifiques de niveau recherche, publiés ou non, émanant des établissements d'enseignement et de recherche français ou étrangers, des laboratoires publics ou privés. 


\title{
PLM in SME, What are we missing? An alternative view on PLM implementation for SME.
}

\author{
Bas Koomen ${ }^{1,2}$ \\ ${ }^{1}$ University of Twente, Enschede, The Netherlands \\ s.p.koomen@utwente.nl \\ ${ }^{2}$ Cadmes b.v., 's-Hertogenbosch, The Netherlands \\ bas@cadmes. com
}

\begin{abstract}
Today, the concept of Product Lifecycle Management (PLM) is widely accepted as strategically important. It is used to manage the increasing complexity of products, processes and organizations. The need to adopt PLM is growing rapidly for Small to Medium-sized Enterprises (SME). PLM implementations are costly and require a lot of effort. The business impact and financial risks are high for SME. Also, SMEs seem to have relatively more difficulties to benefit from PLM. The study at hand addresses the question, based on literature research, why these difficulties exist and how they can be overcome. To answer that question, three sub questions are discussed in this paper. 1) A generic PLM implementation process structure. 2) A list of identified PLM implementation challenges, specific for SME. 3) A classification of PLM research for SME, related to the common PLM implementation process structure. A hypothesis for a PLM implementation failure mechanism in SMEs is formulated, based on the findings. Also, a potential research gap on operational implementation knowledge in SMEs is identified.
\end{abstract}

Keywords: PLM; SME; Implementation

\section{$1 \quad$ Introduction}

Product Lifecycle Management (PLM) is defined as a business activity or strategy. It manages products from their conception to their end-of-live disposal or recycling. This definition is used by industrial institutions like CimData [1] and Gartner Group [2], but also by academic authors like Stark [3, 4], Eigner [5] and Grieves [6, 7]. PLM should not be confused with PLM software that supports processes within PLM. Examples of PLM software are Product Data Management (PDM), Computer Aided Design and Manufacturing (CAD/CAM), Project Management, Workflow Management and Production Planning.

Nowadays, many Small to Medium-sized Enterprises (SME) start to adopt PLM. An SME, as defined by the European Commission [8], is a company with less than 250 employees with an annual turnover up to EUR 50 Million. For PLM implementations, SME specific challenges could also apply to larger companies. 
The importance of PLM for companies grows with the increasing complexity of products, processes and organizations [5], also in SMEs. The introduction of the concept of The Fourth Industrial Revolution or Industry 4.0 intensifies this increase in complexity [9]. Organizations have to work differently than before, if they want to make use of developments like Internet of Things (IoT), Product Service Systems (PSS) or Mass Customization.

Industry and academia have made efforts to improve the methods of PLM implementation. Nevertheless, industry surveys [10-13] show that companies are still struggling to implement PLM successfully. Some authors $[4,14,15]$ claim that $50 \%$ of PLM implementations do not achieve their initial project goals. Unfortunately, no specific definition of project failure or project goals is giving in these references.

For this paper, we analyzed published research about PLM in SME. We searched for PLM challenges and for methods to overcome these challenges. To organize the results, we reviewed publications about PLM implementation and derived a suitable classification structure. The research method is explained in Section 2 and the result can be found in Section 3. In Section 4, we formulate a hypothesis for an SME specific failure mechanism, identify a potential research gap and propose future research.

\section{Research method}

\subsection{Research questions}

The key question in this paper is: "Why do SMEs struggle to implement PLM and what are the proposed solutions in academic literature?". To answer this question we have defined three sub questions:

1. Which implementation methods are described in literature?

2. What are the challenges in PLM implementation, specific for SMEs?

3. Which improvements are proposed in literature?

\subsection{Literature research for PLM implementation guidelines}

A search was done for concepts PLM and Implementation, using Scopus, Web of Science, Google Scholar. We selected papers, specifically on the implementation process, holistically or partially. This selection was based on title, keywords and abstracts. Furthermore, we did a secondary search, using the references in the selected papers. This resulted in an additional number of books, articles, dissertations and industry reports. We derived a generic PLM implementation process structure from this literature to classify the results from the systematic literature review on PLM and SME.

\subsection{Systematic literature review PLM and SME}

We searched in Scopus, Web of Sciences and Google Scholar for both concepts (PLM and SME). Results were left out when SME or PLM had a different meaning than our purpose or when the terms were found only in the references section (Google). We were able to obtain full texts for approximately $50 \%$ of the resulting papers (Table 1). 
Table 1. Literature research results by database.

\begin{tabular}{lcccc}
\hline Database & Hits & Viewed & Relevant & Full text \\
\hline Web of Science & 23 & 23 & 16 & 10 \\
\hline Scopus & 66 & 66 & 48 & 23 \\
\hline Google Scholar & 5970 & 250 & 120 & 71 \\
\hline Total (overlapping) & & & $\mathbf{1 4 8}$ & $\mathbf{7 5}$ \\
\hline
\end{tabular}

We analyzed the retrieved papers in two ways. Firstly, we identified SME-specific challenges that influence the implementation and adoption of PLM.

Secondly, we related the main research topic (contribution) of each paper to one or more steps in the aforementioned generic PLM implementation process structure.

\section{$3 \quad$ Results}

\subsection{Implementation guidelines}

We selected the following publications that contain a holistic description of a PLM implementation process: Stark [3, 4], Eigner et al. [5], Grieves [6, 7], Feldhusen et al. [16, 17], Schuh et al. [18], Bitzer [19] and Arnold et al. [20]. There is a clear structure of preparation, analysis, design and implementation that can be found in all of these publications. We derived a simplified 4-phase structure from these publications, as shown in Table 3 in Section 3.3.

\subsection{SME challenges}

We identified SME specific challenges in the full text papers and organized them in 12 categories. The results are listed in Table 2, ranked by occurrence.

Table 2. SME specific PLM challenges, found in literature.

\begin{tabular}{lcc}
\hline \multicolumn{1}{c}{ SME Challenge } & Sources & References \\
\hline High cost of implementation & 16 & {$[21-36]$} \\
\hline Lack of skilled resources & 11 & {$[22,25,27-31,33,37-39]$} \\
\hline Network dependency & 10 & {$[26,29,33,38,40-45]$} \\
\hline Limited understanding of PLM & 9 & {$[18,22,31,40,43,46-49]$} \\
\hline Informal processes & 9 & {$[33-35,40,44,50-53]$} \\
\hline Informal organizations & 8 & {$[27,33,50,52-55]$} \\
\hline Lack of suitable PLM solutions & 7 & {$[29,33,35,36,38,47,48]$} \\
\hline Unstructured information (flow) & 6 & {$[23,52,55-58]$} \\
\hline Business risk & 5 & {$[33,42,44,50,59]$} \\
\hline PLM complexity & 5 & {$[23,31,33,36,46]$} \\
\hline Unstructured knowledge management & 4 & {$[21,40,50,60]$} \\
\hline Lack of strategic business planning & 1 & {$[43]$} \\
\hline
\end{tabular}




\subsection{Proposed solutions in literature}

After reviewing the papers, we related the research to sub phases in our generic PLM implementation process structure. Classification is based on our interpretation of the main contribution of the papers. This interpretation is intrinsically subjective, also because of variations in structure of the reviewed papers (e.g. case studies, theories, reviews, etc.)

Table 3. Research on PLM in SME, categorized by implementation phase.

\begin{tabular}{|c|c|c|}
\hline Phase/sub phase & Sources & References \\
\hline \multicolumn{3}{|l|}{ 1. Prepare and define } \\
\hline 1.1. PLM Awareness & 5 & {$[42,47,48,61,62]$} \\
\hline 1.2. PLM Vision & 2 & {$[18,63]$} \\
\hline 1.3. Maturity level & 4 & {$[31,49,61,64]$} \\
\hline 1.4. Goals & 2 & {$[18,49]$} \\
\hline 1.5. Strategy & 3 & {$[30,63,65]$} \\
\hline \multicolumn{3}{|l|}{ 2. Analyze and measure } \\
\hline 2.1. Product structure & 2 & {$[37,54]$} \\
\hline 2.2. Processes & 7 & {$[22,38,47,50,52,54,66]$} \\
\hline 2.3. Organization & 4 & {$[52,67]$} \\
\hline 2.4. Infrastructure and ICT & 0 & \\
\hline 2.5. Requirements documentation & 3 & {$[38,47,54]$} \\
\hline \multicolumn{3}{|l|}{ 3. Design } \\
\hline 3.1. Data model & 17 & $\begin{array}{c}{[23,25,26,28,30,36-38,41,45,} \\
46,60,68-72]\end{array}$ \\
\hline 3.2. Processes & 18 & $\begin{array}{c}{[21,26,30,36-38,40,46,53,54} \\
58,67,69-74]\end{array}$ \\
\hline 3.3. Organization & 3 & {$[41,46,53]$} \\
\hline 3.4. Infrastructure and ICT & 7 & {$[24,25,27,37,39,57,59]$} \\
\hline 3.5. Specification documentation & 2 & {$[54,65]$} \\
\hline \multicolumn{3}{|l|}{ 4. Implement and maintain } \\
\hline 4.1. Project management & 2 & {$[54,75]$} \\
\hline 4.2. Vendor selection & 4 & {$[25,32,76,77]$} \\
\hline 4.3. Realization & 2 & {$[37,69]$} \\
\hline 4.4. Customization & 8 & {$[26,35,38,54,62,69,72,74]$} \\
\hline 4.5. Verification & 1 & [27] \\
\hline 4.6. Deployment & 0 & \\
\hline 4.7. Training & 0 & \\
\hline 4.8. Evaluation & 3 & {$[33,56,62]$} \\
\hline
\end{tabular}

\subsection{Interpretation of the results}

Prepare phase. Solutions and challenges are clearly related in the papers related to this phase. Awareness creation aims to overcome the challenge of limited 
understanding of PLM. With insight in the potential of PLM, organizations can build a vision for the future.

Maturity assessment enables organizations to describe the gap that needs to be bridged. Furthermore, better strategic planning and reduction of business risk is possible when the gap is known to the organization. Priorities can be set rationally.

Some papers emphasize the importance of vision, strategy and goals. Nevertheless, little has been written about how an SME can define them practically.

Analysis phase. Analyzing the current state processes and organization of an SME is difficult. This is related to the SME challenge of informal processes and organization.

Generally, SMEs are rigid on a macro level and flexible on an operational level [67]. To overcome this, several new approaches have been proposed to assess these ad-hoc processes, for example by focusing on information flow and collaboration methods.

Design phase. The largest number of papers has been published on the design of process models, data models or on both (ontology). With these process and data models, researchers aim to solve the issue of lacking availability of suitable solutions. They propose industry specific alternatives to the existing models.

Case studies have been done with new PLM models for specific situations. No evidence for a successful universal SME-approach has been presented in the reviewed papers.

Implementation phase. Customization gets most attention in this phase for two reasons. Some papers propose to lower the cost of software by developing a new platform for SME. It is questionable if this is a valid approach, since only $20 \%$ of implementation costs is software cost $[16,20,26]$ and software development is also a cost.

Others see a need for adoption of commercial software to overcome functional deficits for SMEs. This has been studies in specific cases.

In contrast to the high interest in customization, there is less interest in operational aspects of implementation (realization, verification, deployment, training), which has also been observed in a research by Bokinge et al. [78].

\section{Conclusions and future research}

In this paper we discuss answers to the sub questions in Section 2.1. and we formulate a hypothesis for an answer to the main research question.

\subsection{Sub questions}

Sub question 1, Implementation methods. We found a common structure for a generic PLM implementation process in various publications. This process can be very elaborate if all steps are followed consistently, even for large enterprises.

This method also implies that SMEs need to formalize their processes and organization drastically, sacrificing flexibility. Flexibility is a valuable asset of SMEs. 
Sub question 2, Challenges. We have identified 12 SME specific challenges in PLM implementation. This comprehensive list of challenges helps to understand reasons for possible PLM implementation failure in SMEs. Organizations can take these challenges into account in future PLM implementations and manage project risks better.

Sub question 3, solutions in literature. We have seen a variety of approaches to PLM for SME in the papers we reviewed. Our classification in the PLM implementation process structure uncovered hot spots and white spaces in published research. The largest hot spot is data and process modeling, the largest white space, or research gap, is operational implementation knowledge.

\subsection{Main research question}

Commercial PLM systems seem to be developed for reference process models, derived from large enterprises. These reference models often do not fit SMEs (Lack of suitable PLM solutions). Also implementation partners do not have clear answers how to implement PLM for SME [33].

Every SME specific PLM challenge could cause failure, if it is not taken into account during an implementation. Most challenges can be overcome by good project management, following generic PLM implementation guidelines.

The exception is the dilemma between flexibility and formalization. We conclude from our literature research that this challenge needs a alternative approach, compared to large enterprises.

Our hypothesis is that if organizations (companies and implementation partners) are not conscious enough about the aforementioned dilemma between formalization and flexibility, they are at risk. They will start PLM implementations in the "large enterprise style" in expectation that good project management will ensure success. At some point the organization will run into problems with flexibility, leading to increased overhead costs (application management, new administrative work, waiting times, etc.), extensive customization to overcome functional deficits and/or massive rejection by users.

\subsection{Future research}

As a next step, we plan to analyze implementation projects from the past. This qualitative empirical research should give more insight in the influence of the identified PLM implementation challenges in the implementation process in practice. This research can also provide more quantitative data on failure rates of PLM projects, under the condition that a neutral definition of failure can be defined.

Also more research is needed on operational PLM implementation knowledge.

\section{References}

1. CIMdata. About PLM. 2017 [cited 2018 January 16]; Available from: https://www.cimdata.com/en/resources/about-plm. 
2. Gartner. IT Glossary - Product Lifecycle Management. 2018 [cited 2018 January 25]; Available from: https://www.gartner.com/it-glossary/product-lifecycle-management-plm.

3. Stark, J., Product lifecycle management. Volume 1, 21st century paradigm for product realisation. 2015, Springer: Cham.

4. Stark, J., Product lifecycle management. Volume 2, The devil is in the details. 2016, Springer: Cham.

5. Eigner, M. and R. Stelzer, Product Lifecycle Management; Ein Leitfaden für Product Development und Life Cycle Management [Product Lifecycle Management; a guideline for Product Development and Lifecycle Management]. 2009, Springer: Heidelberg.

6. Grieves, M., Product Lifecycle Management: Driving the Next Generation of Lean Thinking. 2005, McGraw-Hilll Education: New York, NY, USA.

7. Grieves, M., Virtually Perfect: Driving Innovative and Lean Products through Product Lifecycle Management. 2011, Merritt Island, FL, USA: Space Coast Press.

8. EuroStat. 2018 [cited 2018 March 1 ]; Available from: http://ec.europa.eu/eurostat/web/structuralbusiness-statistics/structural-business-statistics/sme.

9. The Fourth Industrial Revolution: what it means, how to respond. 2016 [cited 2018 March 05]; Available from: The Fourth Industrial Revolution: what it means, how to respond.

10. AberdeenGroup, The PLM for Small to Medium-Sized Manufacturers Benchmark Report - Enabling Profitable Growth for SMEs. 2006, Aberdeen Group: Waltham, MA.

11. Woo, T., Data Management in PLM: Optimize your Business Performance. 2016, AberdeenGroup: Boston, MA.

12. CIMdata, Cloud PLM: Understanding Adoption Prospects. 2018, CIMData: Ann Arbor, Michigan.

13. Leeder, N., PLMPulse Survey - Edition 2017. 2018, i42R: Utrecht.

14. Wognum, P.M. and I.C. Kerssens-van Drongelen, Process and impact of product data management implementation International Journal of Product Development, 2005. 2(1): p. 5-23.

15. Siddiqui, Q.A., N.D. Burns, and C.J. Backhouse, Implementing product data management the first time International Journal of Computer Integrated Manufacturing, 2004. 17(6): p. 520-533.

16. Feldhusen, J. and B. Gebhardt, Product Lifecycle Management für die Praxis : ein Leitfaden zur modularen Einführung, Umsetzung und Anwendung [Product Lifecycle Management for Practitioners: a guideline for modular implementation and application.]. 2008, Springer-Verlag: Berlin, Heidelberg.

17. Feldhusen, J., et al., Development of methods to support the implementation of a PDMS in Innovation in Life Cycle Engineering and Sustainable Development, D. Brissaud, S. Tichkiewitch, and P. Zwolinski, Editors. 2006, Springer Netherlands: Dordrecht. p. 381-395.

18. Schuh, G.n., et al., Process oriented framework to support PLM implementation Computers in Industry, 2008. 59(2): p. 210-218.

19. Bitzer, M.A., Entwicklung einer Methode zur prozessorientierten Planung und Optimierung von Product-lifecycle-Management-Lösungen : am Beispiel der Automobilindustrie [Development of a Method for Process Oriented Planning and Optimization of PLM Solutions : by Example of the Automotive Industry]. 2008, TU Kaiserslautern: Kaiserslautern. p. 165.

20. Arnold, V., et al., Product lifecycle management beherrschen : ein Anwenderhandbuch für den Mittelstand [Mastering Product Lifecycle Management: a User Manual for Medium Enterprises.]. 2011, Springer: Berlin ;.

21. Arrieta, J.A., A. Azkarate, and N. Aranguren. Advanced Business Intelligence System Adapted to SMEs, Within a Defined Product Life-Cycle Management Frame. in ICE Conference. 2004.

22. Bedolla, J.S., et al., Fostering PLM implementation in SMEs: modelling and managing verification processes IFAC Proceedings Volumes, 2013. 46(9): p. 1762-1767. 
23. Bruno, G., T. Taurino, and A. Villa, MAKO: MAnufacturing Knowledge Organization system to support SME Ifac Papersonline, 2015. 48(3): p. 1559-1564.

24. Cheung, W.M., et al., A Framework for distributed Workflows, Peer-to-Peer and PLM/PDM collaborations to support OEMs and SMEs 2004.

25. David, M.1. and F. Rowe, What does PLMS (product lifecycle management systems) manage: Data or documents? Complementarity and contingency for SMEs Computers in Industry, 2016. 75: p. 140-150.

26. Eigner, M. and F.M. Nem, On the development of new modeling concepts for product lifecycle management in engineering enterprises Computer-Aided Design and Applications, 2010. 7(2): p. 203212.

27. Germani, M., M. Mengoni, and M. Peruzzini, A QFD-based method to support SMEs in benchmarking co-design tools Computers in Industry, 2012. 63(1): p. 12-29.

28. Jardim-Goncalves, R., et al., SMART-fm: setting interoperability in SME-based industrial environments, in Advanced Manufacturing. An ICT and Systems Perspective. 2007, CRC Press. p. 5769.

29. Litvikova, J., M. Rafaj, and S. Valcuha, Product lifecycle in small and medium-sized enterprises Annals of the Oradea University, 2013(1): p. 171-174.

30. Löwer, M. and J.E. Heller, PLM Reference Model for Integrated Idea and Innovation Management in IFIP WG 5.1 International Conference, PLM 2014, S.F.e. al., Editor. 2014, Springer, Heidelberg: Yokohama, Japan,. p. 257-266.

31. Messaadia, M., et al., PLM adoption in SMEs context Computer-Aided Design and Applications, 2016. 13(5): p. 618-627.

32. Ristova, E. and V. Gecevska. AHP methodology and selection of an advanced information technology due to PLM software adoption. in Proceedings of the 15th International Scientific Conference on Industrial Systems. 2011.

33. Saaksvuori, A., PLM vision 2016 and beyond Sirrus Capital Ltd, Helsinki, Finland, 2011.

34. Silventoinen, A., J. Papinniemi, and H. Lampela. A roadmap for product lifecycle management implementation in SMEs. in ISPIM Conference. 2009.

35. Soto-Acosta, P., E. Placer-Maruri, and D. Perez-Gonzalez, A case analysis of a product lifecycle information management framework for SMEs International Journal of Information Management, 2016. 36(2): p. 240-244.

36. Yildiz, O., et al., A Framework for PLM Model Design in IFIP WG 5.1 International Conference, PLM 2013, L.R. A. Bernard, and D. Dutta, Editor. 2013, Springer, Heidelberg: Nantes, France. p. 159-169.

37. Colombo, G., D. Pugliese, and C. Rizzi, Developing DA applications in SMEs industrial context in IFIP International Federation for Information Processing, G.C. Cascini, Editor. 2008. p. 69-82.

38. Le Duigou, J., et al., Generic PLM system for SMEs: Application to an equipment manufacturer International Journal of Product Lifecycle Management 7, 2012. 6(1): p. 51-64.

39. Silcher, S., et al., A Holistic Management Model for Manufacturing Companies and Related IT Support, in Forty Sixth Cirp Conference on Manufacturing Systems 2013, P.F. Cunha, Editor. 2013, Elsevier Science Bv: Amsterdam. p. 175-180.

40. Denkena, B., et al., Knowledge management in process planning Cirp Annals-Manufacturing Technology, 2007. 56(1): p. 175-180.

41. Kadiri, S.E., et al., Collaborative process control: Observation of tracks generated by PLM system arXiv preprint arXiv:0811.1950, 2008.

42. Goto, S., et al., Preliminary study on workshop facilitation for iot innovation as industry-university collaboration PLM program for small and medium sized enterprises in 14th IFIP WG 5.1 International 
Conference on Product Lifecycle Management and the Industry of the Future, PLM 2017, J. Rios, et al., Editors. 2017, Springer New York LLC. p. 285-296.

43. Nupap, S., et al. A framework to lead Thai SMEs to fit international business requirement: Case study of Solution Ceramic Co., Ltd., Thailand. in 2011 4th International Conference on Logistics, LOGISTIQUA'2011. 2011. Hammamet.

44. Pol, G., et al., Implementation of collaborative design processes into PLM systems International Journal of Product Lifecycle Management, 2008. 3(4): p. 279-294.

45. Subrahmanian, E., et al. Challenges in supporting product design and manufacturing in a networked economy: A PLM perspective. in Proceedings of the international conference on product lifecycle management. 2005.

46. Bruno, G., D. Antonelli, and A. Villa, A reference ontology to support product lifecycle management Procedia CIRP, 2015. 33: p. 41-46.

47. Plo, L., V. Robin, and P. Girard, Understanding PLM system concepts to facilitate its implementation in SME: The real case study of POULT in 13th IFIP WG 5.1 International Conference on Product Lifecycle Management for Digital Transformation of Industries, PLM 2016, B. Eynard, et al., Editors. 2016, Springer New York LLC. p. 512-522.

48. Pinna, C., et al., An approach to improve implementation of PLM solution in food industry - case study of Poult Group International Journal of Product Lifecycle Management, 2017. 10(2): p. 151 - 170.

49. Savino, M.M., A. Mazza, and Y. Ouzrout, PLM maturity model: a multi-criteria assessment in southern Italy companies International Journal of Operations and Quantitative Management, 2012. 18(3): p. 159180.

50. Antonelli, D., P. Chiabert, and A. Villa, Introducing Product Lifecycle Management to Small Medium Enterprises: discussion and analysis in IFAC Proceedings Volumes. 2012. p. 1059-1064.

51. Germani, M., M. Mengoni, and M. Peruzzini. A method to define a co-design platform to support cooperative work in SMEs. in Proceedings of the PLM09 conference, Bath, United Kingdom. 2009.

52. Pol, G., Improving design coordination in computer supported environments in SMEs: implementation of a tool for capturing and analysing collaboration between actors. 2008, Cranfield University.

53. Kadiri, S.E., et al., An approach to control collaborative processes in PLM systems arXiv preprint arXiv:0803.0666, 2008.

54. Eynard, B., C. Merlo, and G. Pol. Towards PLM implementation method in SME. in DS 35: Proceedings ICED 05, the 15th International Conference on Engineering Design, Melbourne, Australia, 15.-18.08. 2005. 2005.

55. Medina-Barbosa, D.A. and H.R. Siller. Product Lifecycle Management Model for New Technology Based Enterprises. in International Conference on Cooperative Design, Visualization and Engineering. 2013. Springer.

56. Kaganski, S., M. Paavel, and J. Lavin. Selecting key performance indicators with support of enterprise analyze model. in 9th International Conference of DAAAM Baltic: Industrial Engineering, DAAAMBaltic 2014. 2014. DAAAM International.

57. Basselot, V., T. Berger, and Y. Sallez, Active Monitoring of a Product: A Way to Solve the "Lack of Information" Issue in the Use Phase, in Service Orientation in Holonic and Multi-Agent Manufacturing. 2017, Springer. p. 337-346.

58. Mahdikhah, S., et al., A business process modelling approach to improve OEM and supplier collaboration Journal of Advanced Management Science, 2014. 2(3): p. 246-253.

59. Tähemaa, T., K. Karjust, and M. Pohlak. Erp and plm resources in estonian smes. in 7th International DAAAM Baltic Conference: Industrial Engineering. 2010. DAAAM International. 
60. Bernard, A., F. Laroche, and C. Da Cunha. Models and methods for knowledge formalisation in a PLM context. in 3rd International Congress Design and Modelling of Mechanical Systems CMSM'2009. 2009.

61. Paavel, M., K. Karjust, and J.r. Majak, PLM Maturity Model Development and Implementation in SME 50th CIRP Conference on Manufacturing Systems, 2017, 2017. 63: p. 651-657.

62. Peruzzini, M., M. Mengoni, and M. Germani. PLM benefits for networked SMEs. in The proceedings of 11th International Conference on Product Lifecycle Management. Edited by JH, Pels et al., PLM 11, 11-13 July, 2011, Eindhoven University of Technology. 14 pp. 2011.

63. Paavel, M., et al., Optimizing PLM implementation from vision to real implementation in Estonian SMEs Benefits, 2014. 14: p. 15.

64. Batenburg, R., R.W. Helms, and J. Versendaal, PLM roadmap: stepwise PLM implementation based on the concepts of maturity and alignment International Journal of Product Lifecycle Management, 2006. 1(4): p. 333-351.

65. Kienbaum, G.S., et al. A transdisciplinary process oriented framework to support generic PLM implementation for use by small and medium enterprises. in 23rd ISPE Inc. International Conference on Transdisciplinary Engineering, TE 2016. 2016. IOS Press BV.

66. Le Duigou, J., et al. Specification of a generic PLM system dedicated to SMEs based on a PPRO metamodel. in 16 th CIRP international conference on Life Cycle Engineering. 2009.

67. Pol, G., et al. Prerequisites for the implementation of a product data and process management tool in SME. in ICED 05: 15th International Conference on Engineering Design: Engineering Design and the Global Economy. 2005. Engineers Australia.

68. Bruno, G., et al. Exploitation of a semantic platform to store and reuse plm knowledge. in IFIP International Conference on Advances in Production Management Systems. 2014. Springer.

69. Le Duigou, J., et al., Application of PLM processes to respond to mechanical SMEs needs, in Global Product Development. 2011, Springer. p. 319-326.

70. Le Duigou, J., et al., Generic model for the implementation of PLM systems in mechanical SMEs in International Conferecence on Product Lifecycle Management 2010, K. Thoben, et al., Editors. 2010, Inderscience, Geneva: Bremen, Germany. p. 439-448.

71. Pol, G., et al. From PDM systems to integrated project management systems: a case study. in Proceedings of the International Conference on Product Lifecycle Management, Lyon, France. 2005.

72. Sakao, T., et al. A Method for Lifecycle Design of Product/Service Systems Using PLM Software. in IFIP International Conference on Product Lifecycle Management. 2017. Springer.

73. Cheballah, K. and A. Bissay. Change Management and PLM Implementation. in IFIP International Conference on Product Lifecycle Management. 2013. Springer.

74. Le Duigou, J., et al., Global approach for technical data management. Application to ship equipment part families CIRP Journal of Manufacturing Science and Technology, 2009. 1(3): p. 185-190.

75. Wynn, M.G., Managing IS projects in SMEs-Tailoring the PRINCE2 TM1 methodology 2008.

76. Maranzana, N., et al. Collaborative design tools: a comparison between free software and PLM solutions in engineering education. in IFIP International Conference on Product Lifecycle Management. 2012. Springer.

77. Rocha, L., et al., Cloud management tools for sustainable SMEs Procedia CIRP, 2016. 40: p. $220-224$.

78. Bokinge, M. and J. Malmqvist, PLM implementation guidelines - relevance and application in practice: a discussion of findings from a retrospective case study International Journal of Product Lifecycle Management, 2012. 6(1): p. 79. 